\title{
CHARACTERIZATION OF LOW- TEMPERATURE COAL ASH BEHAVIOUR UNDER ATMOSPHERIC PRESSURE
}

\author{
Manoj B., ${ }^{*}$ Chandrasekharan K.A** \& Kunjomana A.G. ${ }^{* * *}$
}

\begin{abstract}
The chemical composition of the virgin coal from Korba coal fields, South central India is determined with the help of Fourier transform Infrared spectroscopy. The process of burning of carbon rich coal is carried out from a temperature of $200^{\circ} \mathrm{C}$ to $700^{\circ} \mathrm{C}$ under atmospheric pressure and controlled air in a muffle furnace. The resultant coals are examined with FTIR. The result shows that the residence time of coal ash at high femperature has considerable influence on the composition of coal ash and little effect on the amount of unburned carbon. With increase of temperature the oxygenated groups are released mainly as $\mathrm{H}_{2} \mathrm{O}$ and $\mathrm{CO}$, but also as aldehydes, alcohols and acids. The silicate and quartz mineral content remains the same throughout heating.
\end{abstract}

Keywords: Coal, Minerals, Characterization, FTIR

\footnotetext{
* Corresponding author, Lecturer, PG Dept. of Physics, Christ University, Bangalore. E-mail: manoj.b@christuniversity.in.

** Dean of Science, Christ University, Bangalore.

***Professor, PG Dept. of Physics, Christ University, Bangalore.
} 


\section{Introduction}

Fossil energy, particularly derived from coal, has been investigated from many directions. Many environmentalists see coal as inherently disty. Coal minerals are objectionable due to process as well as environmental problems. Coal minerals may be epigenetic and syngentic. Both constitute the inorganic part of the coal and if its concentration increases above a certain level, it is hazardous to the environment and the furnace. Minerals are needed to certain levels due to the catalytic effects in gasification and liquefaction [1 -2]. Efforts are needed to reduce the ash forming inorganic elements and develop clean methods of using coal. Demineralization prior to utilization is an effective way to ensure environmentally friendly combustion of coal as a fuel.

In the present study, FTIR spectra of high volatile bituminous coal from Korba coal field, South central India was analyzed in order to investigate the chemical structure of the semi ranked coals. To study the behaviour of ash from this coal, it is heated at a fixed temperature of $200^{\circ} \mathrm{C}, 400^{\circ} \mathrm{C}, 600^{\circ} \mathrm{C}$ and $700^{\circ} \mathrm{C}$ in a muffle furnace with restricted air supply [3-4]. An FTIR spectrum of each sample is recorded within the wave length range of $4000 \mathrm{~cm}^{-1}$ to $400 \mathrm{~cm}^{-1}$.

\section{Experimental Procedure}

\section{Analysis of the sample}

Coal sample was handpicked from the mine and was kept in open air for about 6 menths at $60 \%$ humidity. For analysis, about $100 \mathrm{~g}$ of the sample was crushed in to a fine powder of about $5 \mu \mathrm{m}$ size. $20 \mathrm{~g}$ of this sample was taken in different china dish for heating in a muffle furnace for different fixed temperatures $200-700^{\circ} \mathrm{C}$. Each sample was heated for about 30 minutes in the furnace for the fixed temperature and allowed to cool slowly in dessicator. $2 \mathrm{mg}$ of this sample was then mixed with $\mathrm{KBr}$ in the ratio $1: 200$ and ground for about 10 minutes. The grinding time and the sample to $\mathrm{KBr}$ ratio 1:200 were kept constant for all the samples under study to ensure uniformity. The mixture was then placed in a $13 \mathrm{~mm}$ diameter die cavity and pressed under high pressure. A portion of each sample was also made into a polished block, according to the standard described by Bustin et al. [5].

The spectra were recorded by using Paragon 500, Perkin-Elmer spectrophotometer in the region $4000-400 \mathrm{~cm}^{-1}$. This spectrometer has the resolution of $4 \mathrm{~cm}^{-1}$. A standard polystyrene film was used for calibration purposes. To obtain consistent records the FT-IR spectra were recorded in 16 scan mode. Kramers-Kronig transformation was applied to each transmittance spectra. 


\section{Results \& Discussion}

\section{FTIR Spectral Analysis of the Coal Samples}

FTIR spectra of virgin coal sample and heated coal sample are shown in Fig. 1.

Sample 1: Virgin coal

Sample 2: Sample heated to $200^{\circ} \mathrm{C}$

Sample 3: Sample heated to $400^{\circ} \mathrm{C}$

Sample 4: Sample heated to $600^{\circ} \mathrm{C}$

Sample 5: Sample heated to $700^{\circ} \mathrm{C}$

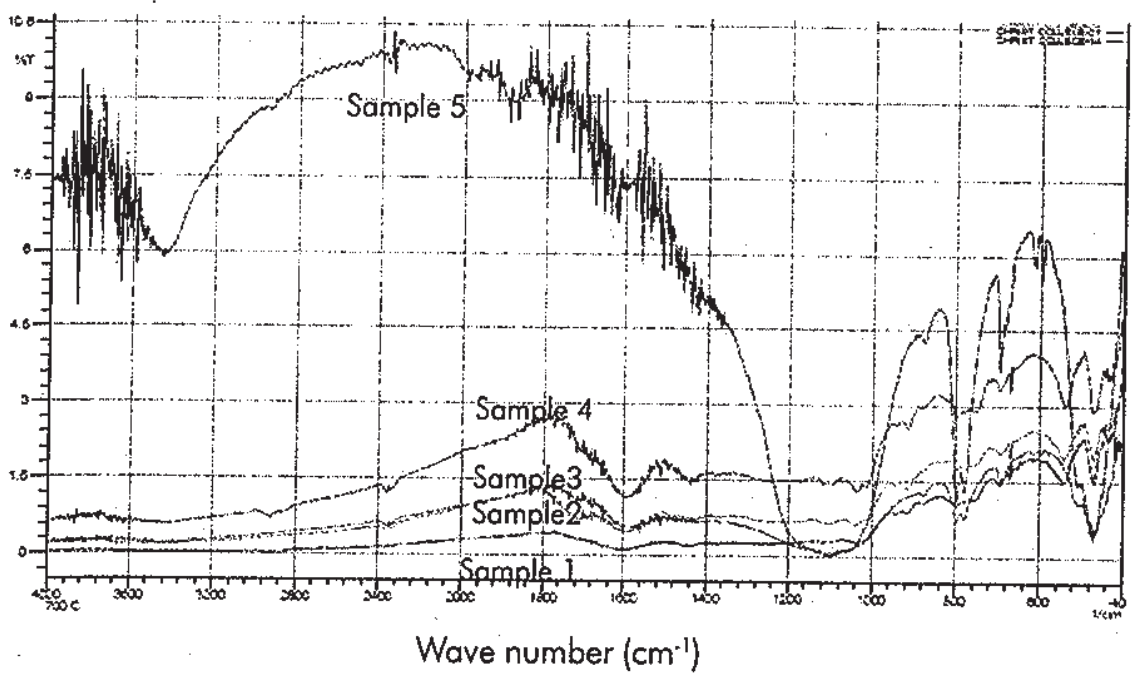

Fig.1. FTIR Spectra of virgin coal and heated coal 
Table 1. FT-iR absorption frequencies, relotive intensity estimate and their assignments

\begin{tabular}{|c|c|c|c|c|c|c|}
\hline \multirow{2}{*}{$\begin{array}{l}\text { Wave } \\
\text { number } \\
\mathrm{cm}^{\prime}\end{array}$} & \multicolumn{5}{|c|}{ Sample } & \multirow{2}{*}{ Assignment } \\
\hline & 1 & 2 & 3 & 4 & 5 & \\
\hline 470 & $w$ & $w$ & $w$ & s & v.s & Clay Minerals / ash \\
\hline 510 & v.w & $v \cdot w$ & v.w & $m$ & $s$ & Bands of silicates \\
\hline 535 & $w$ & $w$ & $w$ & v.w & s & $\mathrm{Si}-\mathrm{O}-\mathrm{Si}$ \\
\hline 669 & $w$ & $w$ & $w$ & $w$ & $w$ & $\begin{array}{l}\text { Band of Silicate Minerals/aromatic out } \\
\text { of plane C.H deformations }\end{array}$ \\
\hline 695 & $\mathrm{~m}$ & $w$ & w & w & $w$ & $\mathrm{Si}-\mathrm{O}$ of $\mathrm{SiO}_{4}$ \\
\hline 795 & $w$ & $w$ & $w$ & s & $s$ & Quartz/C-H bending vibration \\
\hline 935 & $\mathrm{~s}$ & $m$ & $\mathrm{~m}$ & $m$ & $m$ & $\mathrm{OH}$-out of plane bending \\
\hline 10.30 & v.s & s & s & v.s & v.s & $\begin{array}{l}\text { Si-O stretching/C-O stretching from } \\
\text { ether } \& \text { alcahols }\end{array}$ \\
\hline $1080-1120$ & v.s & $s$ & s & v.s & v.s & C-O group \\
\hline 1435 & v.s & $s$ & $s$ & $s$ & $w$ & Methylene group \\
\hline 1605 & v.s & s & v.s & $s^{\prime}$ & s & Aromatic $\mathrm{C}=\mathrm{C}$ Stretching \\
\hline 1690 & v.s & s & $s$ & $\mathrm{~m}$ & $v . w$ & Carboxyl Band \\
\hline 2360 & - & v.s & s & $m$ & $\mathrm{vw}$ & $\mathrm{CO} / \mathrm{CO}_{2}$ evolution \\
\hline 2850 & v.s & v.s & v.s & s. & $w$ & Aliphatic $\mathrm{CH}_{2}$-Stretching vibration \\
\hline 2920 & v.s & v.s & v.s & s & $w$ & Aliphatic $\mathrm{CH}_{3}$-stretching vibration \\
\hline 3400 & v.s & v.s & v.s & $s$ & $w$ & $-\mathrm{OH}$ stretching vibration \\
\hline 3670 & v.s & v.s & v.s & $\mathrm{m}$. & - & $\mathrm{OH}$-in plane degenerated vibration \\
\hline 3700 & $v w$ & V.w & $v w$ & $m$ & - & Clay minerals \\
\hline
\end{tabular}

$\mathrm{vw}=$ very weak; $w=$ weak; $m=$ medium, $s=$ strong; $v s=$ very strong

Each absorption band in the spectra was analyzed for the intensity of transmission by Lambert-Beer law [7] and categorized in to 5 spectral regions, very strong(v.s), strong(s); medium $(m)$, weak( $w)$ and very weak(v.w). Bands were assigned according to published articles [ 1 -6]. The assignments of the prominent bands of IR absorption spectra of five samples are given in table 1 . 
A comparison of the FTIR spectra for the wave number region $400-4000 \mathrm{~cm}^{-1}$ for Korba coal field sample and its chars at four different temperatures is presented in figure 1 .

It is seen from the figure that the samples have more or less similar broad characteristic absorption bands. All the absorption bands are unresolved indicating that the mineral constituents have either large particle size or contain polymeric units. From the figure and intensity table it is seen that all the samples except sample 5 show week absorption bands at $3700 \mathrm{~cm}^{-1}$. This is due to clay minerals present in the sample and are in the form of Kaolinite structure [3,7-8].

The unresolved broad band at $3670 \mathrm{~cm}^{-1}$ is due to the presence of $\mathrm{OH}$ in plane degenerated vibration. The sample shows strong flat band at $3400 \mathrm{~cm}^{-1}$. This band is attributed to the stretching vibration of the hydroxyl group $(-\mathrm{OH})$ due to the water content in the sample. For the samples heated to $200^{\circ} \mathrm{C}, 400^{\circ} \mathrm{C}$ and $600^{\circ} \mathrm{C}$ the same peak becomes slightly weaker, because large amount of the functional group $(-\mathrm{OH})$ still remain in the sample. Some water content in the sample seems to be due to the absorption of air moisture by the sample. The $700^{\circ} \mathrm{C}$ sample presents only a weak peak at the same band because of the remaining $-\mathrm{OH}$ and is due to the decrease in oxygen content with increase in temperature. The same result was reported by Andreas $\mathrm{G}$ et al. $[3,4]$.

In the aliphatic stretching region $\left(3000-2800 \mathrm{~cm}^{-1}\right)$ there are distinct peaks at $2850 \mathrm{~cm}^{-1}$ and $2920 \mathrm{~cm}^{-1}$, attributed to symmetric and asymmetric $-\mathrm{CH}_{2}$ stretching respectively. This peak is distinct up to sample 4 which was treated at $600^{\circ} \mathrm{C}$. The intensity of this particular band decreases as the temperature of the sample was increased to $700^{\circ} \mathrm{C}$ as reported by Andreas $\mathrm{G}$ et al. [3] on low rank Greek coals. All the samples except the virgin coal (samplel) show an absorption peak at $2360 \mathrm{~cm}^{-1}$ due to the liberation of $-\mathrm{CO}$ or $\mathrm{CO}_{2}$ from the sample as the temperature is increased. The maximum evolution of $\mathrm{CO}_{2}$ was taken place at a temperature of $200^{\circ} \mathrm{C}$ and intensity of this peak was reduced to a minimum at $700^{\circ} \mathrm{C}$, because of the complete conversion of coal to ash $[3,4,14]$.

A great abundance of $\mathrm{C}=\mathrm{O}$ and $\mathrm{C}-\mathrm{O}-\mathrm{R}$ structure was noted, as revealed by the intensity of peaks in the $1800-1000 \mathrm{~cm}^{-1}$ region. This zone of oxygen containing functional groups was characterized by a very intense peak at $1605 \mathrm{~cm}^{-1}$, which was attributed to either $\mathrm{C}=\mathrm{C}$ or $\mathrm{C}=\mathrm{O}$ aromatic ring stretching vibrations. The $\mathrm{C}=\mathrm{C}$ bands, which should be placed between $\mathrm{C} \cdot \mathrm{O}$ and $\mathrm{C}=\mathrm{O}$ bands, were not definitely distinguished, since the low rank coals have high oxygen content and these bands almost masked the $C=C$ structures. The same was reported by Thomasson et al. [9]. The intensity of this band decreases with increase of temperature of the sample up to $600^{\circ} \mathrm{C}$. The peak was distorted at $700^{\circ} \mathrm{C}$, due to the reason that the sample was changed to ash. 
At the $1200-1000 \mathrm{~cm}^{-1}$ region, a sharp, intense peak were present in all the samples. The C-O groups in the $1080-1120 \mathrm{~cm}^{-1}$ and $1030 \mathrm{~cm}^{-1}$ region were also very distinct. The $1030 \mathrm{~cm}^{-1}$ may also result from silicate minerals (Si-O bonds). As the temperature of the sample increases from $200^{\circ} \mathrm{C}$ to $600^{\circ} \mathrm{C}$, the intensity of this band decreases accordingly as reported by Guo and Bustin [10]. But surprisingly at $700^{\circ} \mathrm{C}$, the band shows a sudden increase in its intensity. This is due to the presence of silicate mineral, clay and ash. This is reported by Cetinkaya and Yurum [11]. From this we can infer that the coal sample, while heating, produces ash with more minerals in it.

In addition to the observed bands at $1605 \mathrm{~cm}^{-1}$ broad band at $1435 \mathrm{~cm}^{-1}, 11.20$ $\mathrm{cm}^{-1}$ and a band at $1030 \mathrm{~cm}^{-1}$ has been observed in all the samples. These bands observed in this region show that the coal samples constitute complex polymeric materials. The absence of the band at $1500 \mathrm{~cm}^{-1}$ was due to benzene rings and its disappearance reveals that the Korba field coals are older than Neyveli lignite and Godavari kani coals [12-13].

The distinct peak at $669 \mathrm{~cm}^{-1}$ in the entire sample was attributed to the presence of mineral matter (silicates) than aromatic out of plane bending, because its intensity remains the same in the FTIR spectra throughout the heating. In other words heating can not remove this particular mineral from the coal sample.

It is observed that the penetration depth for the $\mathrm{C}$-H stretching bands near $3000 \mathrm{~cm}^{-1}$ is around $a$ quarter of that of the $-\mathrm{CH}$ bending vibration near $800 \mathrm{~cm}^{-1}$. The intensity of the bands is directly related to the penetration depth which in turn directly related to wavelength [9].

The bands at $470 \mathrm{~cm}^{-1}$ and $510-530 \mathrm{~cm}^{-1}$ could be related to the presence of clay, ash and silicate minerals.

The intensity of the mineral bands (in the $400-600 \mathrm{~cm}^{-1}$ and $3600-3800 \mathrm{~cm}^{-1}$ zone) were more or less remains the same throughout heating except at $700^{\circ} \mathrm{C}$ in the FTIR spectra of the samples.

Aliphatic bands $\left(3000-2800 \mathrm{~cm}^{-1}\right)$ and oxygenated functional groups $\left(1800-1000 \mathrm{~cm}^{-1}\right)$ show lower intensity with increase in temperature of the sample $[3,4,14]$. 


\section{Conclusion}

FTIR spectroscopy was applied to high volatile bituminous coal from Korba coal from south central India at. 4 different final temperatures, in order to investigate their chemical structure. The study reveals a great abundance of C-O and C-O-R structures (1800-1000 $\mathrm{cm}^{.1}$ region), while clay and silicate minerals were identified in the $400-600 \mathrm{~cm}^{-1}$ and $3600-3800 \mathrm{~cm}^{-1}$ zone. The intensity of the mineral band remains the same in all the samples except sample 5. The aliphatic bands $(3000$ $\left.2800 \mathrm{~cm}^{-1}\right)$ showed a lower intensity with increase of temperature. Major quantity of $\mathrm{H}_{2} \mathrm{O}$ is at the wave number of $3400 \mathrm{~cm}^{-1}$. A strong peak at $1030 \mathrm{~cm}^{-1}$ in the entire sample is the evidence of the presence of phenolic and alcoholic $\mathrm{C}-\mathrm{O}$ bonds as well as $\mathrm{C}-\mathrm{O}-\mathrm{C}$ bonds with aliphatic or aromatic carbons. At $700^{\circ} \mathrm{C}$ the same peak is showing a sudden change in intensity, may be due to the presence of silicate minerals in the sample. The absorption peak at the wave number $2360 \mathrm{~cm}^{-1}$ reveals the evolution of $-\mathrm{CO}$ and $\mathrm{CO}_{2}$ from the sample while heating. The evolution of $\mathrm{CO}_{2}$ is maximum at $200^{\circ} \mathrm{C}$ and thereafter it decreases with increase of temperature. The absence of the band at $1500 \mathrm{~cm}^{-1}$ shows that they are older coal. It is observed that the penetration depth for the $\mathrm{C}$-H stretching bands near $3000 \mathrm{~cm}^{-1}$ is around a quarter of that of the $-\mathrm{CH}$ bending vibration near $800 \mathrm{~cm}^{-1}$. The intensity of the bands is directly related to the penetration depth which in turn directly related to wavelength.

\section{References}

1. Huttinger, K.J., and Krauss, W., Catalytic octivity of coal minerals in hydrogasification of coal. Fuel, 60, 93, (1981).

2. Montano, P.A., Bommannavar, A.S., and Shah, V., Mössbaver study of transformations of pyrite under conditions of coal liquefaction. Fuel, 60, 703, (1981).

3. de la Puente, G., Iglesias, M.J., Fuente, E., and Pis, J.J., Changes in the structure of coals of different rank due to oxidation effects on pyrolysis behaviour. Journal of Analytical and applied pyrolysis, $47(1): 33,(1998)$.

4. Andreas, Georgakopoulos., Andreas, lordanidis., Victoria, Kapina., Study of low rank Greek coals using FTIR Spectroscopy. Energy sources, 25, 995, (2003)

5. Bustin, R, M., Cameron, A., 'Coal Petrology, Its Principles, Methods and Applications', Geological Association of Canada, Short Course Notes, $2^{\text {nd }}$ Edn, (1985).

6. Das, T.K., Evolution characteristics of gases during pyrolysis of maceral concentrates of Russian coking coals. Fuel, 80, 489, (2001).

7. Cerny, J. Structural dependence of $\mathrm{CH}$ bond absorptivities and consequences for FT-ir analysis of cools. Fuel, 75,1301, (1996). 
8. Alcañiz-Monge, J., Cazorala-Amorós, D., Linares-Solaño., characterization of coal tar pitches by thermal analysis, infrared spectrosciopy and solvent fractionation. Fuel, 80, 41, (2001).

9. Thomasson, J., Coin, C., Kahraman, H., and Fredericks, P, M., Attenuated total reflectance infrared microspectroscopy of coal. Fuel, 79, 685, (2000).

10. Guo, Y, and R. M. Bustin., FTIR spectroscopy and reflectance of modern charcoals and fungal decayed woods: Implications for studies of inertinite in coals. International Journal of Coal Geology, 37, 29 (1998).

11. Cetinkaya, S., and Yurum, Y., Oxidative pyrolysis of Turkish lignites in air up to $500^{\circ} \mathrm{C}$. Fuel Proc. Technol. 67 (3), 177 (2000).

12. Manoj, 8., Chandrasekharan, K,A., and Kuniomana, A,G., Characterization of Coal samples from Godavarikani deposits using FTIR spectroscopy. Mapana Journal of sciences, $7,41(2008)$.

13. Venkatachalapathy, R., and Ramaswamy, K., FTIR study of Neyveli lignite. Asian Chemistry Letters, 3, 160-166 (1999).

14. Jin, Bai., Wen, Li., and Baoging, Li., Characterization of low temperature coal ash behaviour under reduced pressure. Fuel, 87, 583, (2008). 